\title{
Paternal Self-Efficacy: A Parenting Resilience Factor for Fathers with Depression
}

\author{
Mark Herrick Trahan \\ Texas State University - San Marcos \\ Kevin Shafer \\ Brigham Young University - Provo, kshafer@byu.edu
}

Follow this and additional works at: https://scholarsarchive.byu.edu/facpub

Part of the Family, Life Course, and Society Commons

\section{Original Publication Citation}

Trahan, M.H. \& Shafer, K. (2019). “Parental Self-Efficacy: A Parenting Resilience Factor for Fathers with Depression." Social Work Research, 43(2): 101-114.

\section{BYU ScholarsArchive Citation}

Trahan, Mark Herrick and Shafer, Kevin, "Paternal Self-Efficacy: A Parenting Resilience Factor for Fathers with Depression" (2019). Faculty Publications. 4415.

https://scholarsarchive.byu.edu/facpub/4415

This Peer-Reviewed Article is brought to you for free and open access by BYU ScholarsArchive. It has been accepted for inclusion in Faculty Publications by an authorized administrator of BYU ScholarsArchive. For more information, please contact ellen_amatangelo@byu.edu. 


\title{
Paternal Self-Efficacy: A Parenting Resilience Factor for Fathers with Depression
}

\author{
Mark Herrick Trahan and Kevin Shafer
}

\begin{abstract}
Parental depression has a negative effect on child development including mental and physical health, language and development, and externalizing and internalizing behavior. This quantitative research study examined the relationship between paternal self-efficacy (PSE) and parenting behaviors often associated with paternal depression. Data from the Survey of Contemporary Fathers were used and responses from self-identified fathers $(n=1,156)$ on paternal involvement, warmth, harsh parenting practices, and parenting self-efficacy were analyzed to assess the association between depression and PSE on fathering behavior. Ordinary least squares regression analysis indicated that depression was associated with harsh parenting and parenting warmth, while parenting self-efficacy was associated with warmth. PSE moderated the relationship between depression and warmth, indicating a potential resilience factor for neglectful parenting practices in fathers who are depressed. Parenting self-efficacy did not moderate the relationship between depression and harsh parenting, indicating that it may serve well as a resilience factor for fathers with low engagement rather than for fathers with high negativity.
\end{abstract}

KEY WORDS: depression; father involvement; parenting behavior; parenting self-efficacy

$\mathrm{D}$ epression is the most common mental health problem in the United States. Within the general population, nearly $7 \%$ of individuals will experience a depressive episode in a given year and almost one in five Americans will be clinically depressed in their lifetime (Kessler et al., 2003). Compared with nonparents, parents are at an increased risk of depression (National Research Council \& Institute of Medicine, 2009). During a child's early ages, while negotiating new responsibilities and shifting roles in intimate partnerships, parents are at increased risk for decreased sleep, stress, and other issues associated with an increased risk for becoming depressed (Singley \& Edwards, 2015). For fathers, the risk for depression begins early, with one out of 10 experiencing clinical depression in the period from pregnancy to postpartum (Cameron, Sedov, \& Tomfohr-Madsen, 2016; Paulson \& Bazemore, 2010). Longitudinal analysis of fatherhood depression during school age and adolescent years suggests that fathers may experience even greater levels of depression during their child's adolescent years (Garfield et al., 2014). The likelihood of depression increases for fathers during the first five years of a child's life, while approximately $8 \%$ of fathers may experience continued depression throughout the life of their child (Garfield et al.,
2014; Giallo, D’Esposito, Cooklin, Christensen, \& Nicholson, 2014).

Although parental depression has been identified as a significant public health issue (Greenberg, Fournier, Sisitsky, Pike, \& Kessler, 2015; McLaughlin, 2011), current understanding of parental depression and its influence on children and families is largely limited to maternal depression. These studies show that maternal depression is associated with negative effects on children, including reduced birthweight and developmental delay (Surkan, Kennedy, Hurley, \& Black, 2011), internalizing and externalizing behavior, psychopathology (Goodman et al., 2011), and poor health outcomes (Lampard, Franckle, \& Davison, 2014). Paternal depression has only recently received scholarly attention (Shafer, Fielding, \& Wendt, 2017), perhaps due to shifting expectations in gender roles and increased paternal involvement within families (Bianchi, Robinson, \& Milke, 2006). Furthermore, depressive symptoms vary by gender (Shafer \& Wendt, 2015), suggesting that research should address the unique nature of both maternal and paternal depression on parenting (Shafer et al., 2017).

Depressed parents seemingly parent differently than those who are not depressed; depression appears to be associated with fewer positive parenting behaviors and increased negative interactions 
with children (Shafer et al., 2017; Wilson \& Durbin, 2010). This issue may be particularly salient among fathers, because many men often manifest their depressive symptoms externally through anger, withdrawal, violence, substance abuse, and other problematic behaviors (Addis, 2008). With respect to parenting, for example, depression has been linked to decreased parental warmth and increased potential for neglect (Bronte-Tikew, Moore, Matthews, \& Carrano, 2007; Epkins \& Harper, 2016). Depressed fathers may display low levels of engagement, caregiving, play, and other activities that are beneficial for child development (C. Baker, 2014; Nath, Russell, Ford, Kuyken, \& Psychogio, 2015). At the same time, depressed fathers are also more likely to become hostile and negative, engaging in harsh parenting practices (Bronte-Tikew et al., 2007; Epkins \& Harper, 2016; Leung \& Slep, 2005; Nath et al., 2015). Children with depressed fathers are at an increased risk for depression and other mental health challenges, including increased internalizing and externalizing problem behaviors (Giallo et al., 2014; Kotch et al., 2014; Morris \& Oosterhoff, 2016; Nath et al., 2015; Pilowsky et al., 2014). Furthermore, they may experience delayed development and learning and report poorer physical health than children without a depressed parent (Gladstone, Beardslee, \& Diehl, 2015; Goodman et al., 2011). Given the associations between father depression and negative child outcomes, it is important to identify factors that promote parenting resilience for fathers with depression.

\section{SELF-EFFICACY THEORY}

One possible resilience factor for depressed fathers is paternal self-efficacy (PSE). Bandura (1977) introduced the concept of self-efficacy as a precursor to positive performance in various life domains, hypothesizing that greater self-efficacy positively affects corrective actions to overcome barriers to positive performance during adverse experiences. Paternal self-efficacy is a father's appraisal of his competence as a parent (Sevigny \& Loutzenhiser, 2010) and beliefs in the capabilities of provision in specific parenting tasks (Glidewell \& Livert, 1992; Wittkowski, Garrett, Calam, \& Weisberg, 2017). Unlike mothers, who build self-efficacy during the prenatal period, fathers are more likely to be involved and efficacious in their parenting if they engage with their child in the child's first two months of life (Leerkes \& Burney, 2007; Tremblay \& Pierce, 2011).
Prior studies show that men's confidence in their parenting is associated with increased involvement with their children. In a sample of U.S. fathers, self-efficacy proved to be a strong predictor of father involvement, perhaps more than interpersonal factors (for example, co-parenting alliance, marital satisfaction) (Trahan, 2018), a finding noted in international samples as well (Kwok, Ling, Leung, \& Li, 2013). Furthermore, PSE appears to be associated with increased parenting control, reducing hostility and coercive parenting techniques (Murdock, 2013). Increased paternal involvement with children has well-established child outcomes, including decreased externalizing behavior, increased education attainment and occupational mobility, positive physical and mental health, and greater emotional development (Flouri, 2005).

In accordance with self-efficacy theory, PSE has been theorized to boost positive father involvement in adverse situations (Trahan, 2018). Parenting selfefficacy may moderate the relationship between adverse situational experiences and parental engagement. For instance, compared with fathers living in peaceful nations, fathers with daily exposure to violent military conflict are more likely to be involved and efficacious with their children, potentially as a function of their self-efficacy as protectors (PagorekEshel \& Dekel, 2015). Fathers of children with disabilities are more likely to experience well-being when they feel efficacious in the parenting realm (Boyraz \& Sayger, 2011). Although it is uncertain whether a father's general self-efficacy translates to self-efficacy within the parenting realm (Murdock, 2013; Sevigny \& Loutzenhiser, 2010), PSE may be a resilience factor that moderates the relationship between depression and negative parenting practices.

\section{THE PRESENT STUDY}

The purpose of this study was to investigate the relationship between depression and PSE. As evidence exists that depression may contribute to harsh parenting or neglect (Epkins \& Harper, 2016), these factors were examined in the analysis. First, this study investigated the role that PSE has on the relationship between depression and harsh parenting. As links have been found between these variables, PSE was identified as a potential moderator in the relationship between these factors. We hypothesized that depressed fathers with greater levels of PSE would be less likely to exhibit harsh parenting practices. Second, this study examined 
the relationship between depression, warmth, and PSE. As depression has been linked to emotional neglect in parenting, we examined the relationship between PSE and the warmth for depressed fathers, hypothesizing that depression would significantly associate with levels of paternal warmth. Using Bandura's (1977) theory as a basis for hypothesis, we postulated that self-efficacy would moderate the relationship between emotional state and parenting behavior. Thus, we proposed that PSE would moderate the relationship between depression and parenting warmth.

\section{METHOD}

\section{Data Collection and Participants}

Data for this study came from the Survey of Contemporary Fatherhood (SCF) (Shafer, Fielding, \& Holmes, 2019), a 2015 survey addressing factors that discourage and encourage involved fatherhood in the United States. SCF was approved by the institutional review board at Brigham Young University. SCF is a national sample of nearly 2,300 biological fathers, stepfathers, and father figures in the United States collected by a team of investigators from universities across the United States. Eligibility requirements for SCF included (a) the respondent had to be 18 or older; (b) the respondent had to be a biological (residential or nonresidential) father, adoptive (residential or nonresidential) father, residential stepfather, a residential unrelated father figure (defined as living with a nonbiological, nonadopted child in a home with the child's biological or adoptive mother, but not in a marital relationship), or a residential father figure who is related to the child by biology, marriage, or adoption (that is, a grandfather or uncle); (c) have English proficiency, as some scales included in SCF lack non-English translations; and (d) the ability to access the survey on the Internet. Fathers responded to questions about a focal child, defined as the youngest eligible child in the home between the ages of 2 and 17 years.

SCF used quota sampling procedures. Quota samples are often used due to time and cost efficiency. Quota samples can produce samples like probability sampling (Weinberg, Freese, \& McElhattan, 2014), but may also produce samples that are nonequivalent, thus not representative (Yang \& Banamah, 2014). Thus, quota samples should be considered exploratory. Data were collected by a Qualtrics opt-in online panel, recruited through online and other advertising, and screened for eligibility through an online registration form. Respondent candidates were randomly selected by Qualtrics from a pool of approximately 100,000 potential participants and contacted via e-mail by Qualtrics to request participation. Panelists are restricted in the number of surveys they may complete in a year, must regularly update their information to remain in the panel, and are monitored on sociodemographic questions to ensure consistency across responses. Respondents were provided a link to the survey screening site, where final eligibility was determined based on three categories: race and ethnicity, paternal relationship with child, and geographical residence. Quotas of population characteristics were drawn from population estimates from the 2011-2014 American Community Survey (U.S. Census Bureau, 2016a). Upon meeting eligibility requirements, respondents were invited to complete the survey.

Several data quality checks were used in SCF, including attention filters (that is, "trap questions"), identification of careless respondents, safeguards against multiple submissions, and survey length minimums. These strategies were used in accordance with the best practices in online data collection guidelines set forth by the American Association for Public Opinion Research (R. Baker et al., 2010). Multiple demographic characteristics were also used in the sampling scheme and screening process to reduce the possibility of biased results (Smith, Roster, Linda, \& Gerald, 2016; Terhanian, Bremer, Olmsted, \& Guo, 2016). Finally, postcollection data quality checks were performed with a focus on parent age, child age, and other openended questions. These post hoc data quality checks removed approximately $4 \%$ of respondents from the sample. The final sample size was 1,156.

Prior research has shown that online opt-in panels are relatively representative of individuals with regular access to the Internet (Tourangeau, Conrad, \& Couper, 2013). Yet, one concern with online panels is that they may exclude or underrepresent marginalized groups. Although it is unclear what the overall Qualtrics panel looks like at any given point in time, the 2012 Current Population Survey found that slightly more than $80 \%$ of adult Americans had regular access to the Internet, and racial gaps in Internet usage have closed considerably since 2012, although gaps due to income, education, and rural versus urban communities persist (Pew Research Center, 2016). In general, the demographic estimates from the full SCF sample were like those from other national data 
sets. For example, fathers in the SCF appear to be similar with respect to race and ethnicity, education, and income to fathers in nationally representative data recently collected by Pew Research (Survey of American Parents) and on residential status in the National Survey of Family Growth (Shafer et al., 2019). Despite these similarities, nonresident fathers, fathers with low socioeconomic status (SES), and racial and ethnic minorities are underrepresented in the SCF. Thus, results from this study are not nationally representative. However, the quality of measures used and the large national sample still provide useful exploration into the potential associations between PSE, depression, and parenting behavior.

\section{Dependent Variables}

Paternal Warmth. The measure for paternal warmth was formed from eight items on the frequency of specific parenting behaviors in the past month. These items came from measures available in the Early Childhood Longitudinal Study-Birth (ECLS-B) and the Head Start Child Study. The items included on this measure were (a) expressing affection (that is, "I express my affection by holding, kissing, or hugging my child"), (b) praising the child (that is, "I praise my child by saying something like 'good for you', "thank you', or something similar"), (c) relaxing while parenting (that is, "I am easy going and relaxed with my child"), (d) smiling at child (that is, "I smile at my child often"), (e) affectionate use of nicknames (that is, "I give my child affectionate nicknames"), (f) bragging about the child (that is, "I brag about my child to my friends and family"), (g) thinking about the child (that is, "I often think about my child"); and (h) holding the child (that is, "I think holding and cuddling my child is fun"). Each item was assessed on a fivepoint Likert scale ranging from $0=$ never to $4=$ at least once a day. Items were then combined into a continuous scale for warmth, ranging from 0 to 32 . This scale demonstrates high internal consistency $(\alpha$ $=.87$ ). Prior research has also validated these measures through exploratory and confirmatory factor analyses (see Petts, Shafer, \& Essig, 2018).

Harsh Parenting. Harsh parenting was measured with three items from the parental control and discipline scales used in the ECLS-B. Three items asked parents to indicate how likely they would be to spank the child, hit the child, or make fun of the child if the child needed discipline. Respondents were asked to rate the likelihood of the punishment on a four-point Likert-type scale ranging from $0=$ not likely to $3=$ very likely. Items were combined into a continuous scale for harsh parenting, ranging from 0 to 9 . The scale demonstrates good internal consistency $(\alpha=.77)$. As with warmth, this measure was previously validated with exploratory and confirmatory factor analyses (see Petts et al., 2018; Shafer et al., 2019).

\section{Key Independent Variables}

Depression. Depression was measured with the 20-item Center for Epidemiological Studies Depression Scale (Comstock \& Helsing, 1976), which addresses the frequency of both internalized (for example, "I had trouble keeping my mind on what I was doing") and externalized (for example, "I did not feel like eating, my appetite was poor") symptoms over the last week. For each of the 20 items on the scale, respondents were asked to indicate how frequently they experienced the depressive symptom on a four-point Likert scale ranging from $0=$ did not experience in the last week to $3=$ experienced every day or almost every day in the last week. Using standardized scoring instructions for this scale, results were calculated by summing all 20 items into a continuous variable ranging from 0 to 60 . This scale demonstrates high internal consistency $(\alpha=.93)$.

PSE. PSE was measured with a single item. Respondents were asked how often they felt they could not handle being a parent, on a five-point Likert scale ranging from $1=$ never to $5=$ very often. As very few respondents $(<5 \%)$ indicated that they rarely (a value of 2 on the scale) or very often felt they could not handle being a parent, the "rarely" category and the "never" category were combined, and the "very often" category was combined with the "often" category. As a result, PSE was measured by a categorical variable with values indicating whether the fathers never or rarely felt they could handle being a parent (that is, low paternal efficacy), sometimes felt they could not handle being a parent (that is, average paternal efficacy), and often or very often felt they could handle being a parent (that is, high paternal efficacy).

\section{Control Variables}

Based on the ecological model of father involvement (Cabrera, Fitzgerald, Bradley, \& Roggman, 2014), analysis included several measures of 
paternal, child, and family characteristics that may influence fathering behavior. Demographic variables related to outcome variables were included; specifically, father's racial and ethnic identity, age (Blackwell, Lucas, \& Clarke, 2014; Kim, DeCoster, Huang, \& Chiriboga, 2011), educational attainment, income, SES (Bornstein \& Bradley, 2014; Elliott, 2001), and employment status were measured with dichotomous variables. As child and family characteristics have previously been studied in relation to warm parenting, father involvement, and the use of harsh parenting (Lee, Altschul, \& Gershoff, 2015), control measures included total number of children, whether child was biological (reference) or nonbiological, child gender, and parenting resident status (residing or not residing).

Closed maternal gatekeeping is associated with barriers that can prevent many fathers from caring for and nurturing their children (Allen \& Hawkins, 1999). To control for this variable, we used an adapted form of the Maternal Gatekeeping Scale (Fagan \& Barnett, 2003) for self-report by the father, which asked fathers if they felt the child's mother was engaged in gatekeeping, preventing them from being involved in the disciplining (for example, "If my child needs to be disciplined, the mother should discipline him or her, not me"), schooling (for example, "If someone needs to talk to the child's teacher, the mother should do it, not me"), caregiving (for example, "If my child has to go to the doctor, the mother should take him or her, not me"), emotional work (for example, "If my child's feelings are hurt, the mother should comfort him or her, not me"), and decision making with their child (for example, "If a decision has to be made about who my child will play or spend time with, the mother should make that decision, not me"). Each of the nine items was measured on a five-point Likert scale ranging from $0=$ strongly disagree to $4=$ strongly agree. These items were combined to create a scale ranging from 0 to 36 $(\alpha=.96)$, with higher scores indicating that the fathers felt mothers were stronger gatekeepers.

Co-parenting is a measure indicating how willing the father was to engage in cooperative and supportive parenting with the child's mother (Palkovitz, Fagan, \& Hull, 2013) and may influence parenting engagement. To measure co-parenting, the fiveitem co-parenting scale available in the Fragile Families and Child Wellbeing Survey was replicated (for example, "You and the mother of the child talk about problems that come up with raising the child"). Each item was measured on a threepoint Likert scale ranging from $0=$ never to $2=$ always. The combined scale $(\alpha=.90)$ ranged from 0 to 10 , with higher scores indicative of higher coparenting.

\section{Analytic Strategy}

Ordinary least squares (OLS) regression was used to assess the association between depression and paternal efficacy on fathering behavior. OLS was chosen over alternative modeling strategies, such as structural equation modeling, because of the ease with which moderating relationships can be modeled and interpreted. Analysis included three sets of models for each of the outcomes. The first model was a main effects model that included our measures of depression and paternal efficacy and all the control variables. The second model was an interactive model that included an interaction between depression and paternal efficacy. Following the recommendations of Hoffmann and Shafer (2015), continuous measures (depression) were standardized in the interactive models.

Several diagnostic tests for our OLS regressions indicated that assumptions were met. Ramsey's RESET test (Hoffmann \& Shafer, 2015) indicated that there was no omitted variable bias in our models. According to variance inflation factors tests, collinearity and multicollinearity were not present in our model. The Breusch \& Pagan (1980) and White's test (1980) both indicated the presence of heteroskedasticity in the model. Alternative variable specifications for the depression did not reduce heteroskedasticity in our models. As a result, analysis included the Huber-White sandwich estimator (Huber, 1967) to correct standard errors that have the potential for overprecision and increasing the likelihood of Type I errors. Tests for outliers and leverage points (studentized residuals, Cook's D, leverage values, and DFFITS) indicated the presence of six problematic respondents, which were excluded from all models. Less than $3 \%$ of our data were missing, and Little's (1988) test indicated that missing values were missing completely at random. Nevertheless, listwise deletion eliminated the small number of missing values, reducing the sample size from 1,172 to 1,156. Descriptive statistics, including the demographic characteristics of the sample, are reported in Table 1. 


\section{RESULTS}

Results from the main effects OLS models are reported in Table 2. The results indicate that depression was associated with paternal warmth in this sample. More specifically, a one-point increase in depression score was associated with a 0.052-point decrease in warmth $(p<.01)$. Using standard cutoffs for the interpretation of magnitude for standardized regression coefficients (Hoffmann \& Shafer, 2015), the effect size was small in magnitude, with a standardized regression coefficient of 0.113 (results not shown, but available upon request). Results indicate that fathers with lower levels of paternal efficacy exhibited lower levels of warmth toward their

\begin{tabular}{|c|c|c|c|}
\hline Variable & $\begin{array}{l}\text { M or } \\
(\%)\end{array}$ & SD & $\begin{array}{l}n \text { or } \\
\text { Range }\end{array}$ \\
\hline Paternal warmth & 25.346 & 5.259 & $0-32$ \\
\hline Harsh parenting & 1.334 & 1.882 & 0-9 \\
\hline \multicolumn{4}{|l|}{ Paternal efficacy } \\
\hline High & $(25)$ & & 293 \\
\hline Average & $(42.3)$ & & 496 \\
\hline Low & $(32.7)$ & & 383 \\
\hline Depression score & 14.348 & 11.603 & $0-60$ \\
\hline \multicolumn{4}{|l|}{ Race/ethnicity } \\
\hline Non-Hispanic white & $(7.0)$ & & 815 \\
\hline Non-Hispanic black & $(9.8)$ & & 115 \\
\hline Latino/Hispanic & 13.3 & & 156 \\
\hline Other racial/ethnic identity & $(7.3)$ & & 86 \\
\hline Father's age & 35.196 & 8.239 & $18-70$ \\
\hline$\$ 0-\$ 20,000$ & $(9.4)$ & & 110 \\
\hline$\$ 20,001-\$ 40,000$ & $(22.1)$ & & 259 \\
\hline$\$ 40,001-\$ 60,000$ & $(24.4)$ & & 286 \\
\hline$\$ 60,001-\$ 80,000$ & $(19.3)$ & & 226 \\
\hline$\$ 80,001-\$ 100,000$ & $(9.2)$ & & 108 \\
\hline More than $\$ 100,000$ & $(15.6)$ & & 103 \\
\hline \multicolumn{4}{|l|}{ Father's education } \\
\hline Less than high school & $(7.3)$ & & 85 \\
\hline High school graduate & $(13.7)$ & & 161 \\
\hline Some college & $(35.2)$ & & 413 \\
\hline College graduate or more & $(43.8)$ & & 513 \\
\hline Father is unemployed & $(14.8)$ & & 171 \\
\hline \multicolumn{4}{|l|}{ Total number of children } \\
\hline 1 & $(30.6)$ & & 359 \\
\hline 2 & $(37.0)$ & & 434 \\
\hline 3 & $(16.9)$ & & 198 \\
\hline 4 or more & $(14.1)$ & & 165 \\
\hline Child is nonbiological & $(12.1)$ & & 140 \\
\hline Child is female & 0.411 & & 482 \\
\hline Child is nonresidential & 0.055 & & 65 \\
\hline Closed maternal gatekeeping & 10.842 & 7.490 & $0-36$ \\
\hline Co-parenting & 7.974 & 2.388 & $0-10$ \\
\hline
\end{tabular}

children. Fathers with average paternal efficacy had warmth scores 1.212 points lower than fathers with high efficacy $(p<.001)$. Fathers who reported low paternal efficacy had warmth scores 2.454 points lower than fathers with high efficacy $(p<.001)$. Supplementary analyses indicated a statistically significant $(p<.01), 1.192$-point difference between the average and low efficacy groups. Among the control variables, fathers with older children and nonbiological children exhibited lower levels of warmth. Likewise, closed maternal gatekeeping was negatively associated with paternal warmth. The fathers of daughters reported that they were warmer toward their children than fathers with sons. Similarly, co-parenting was positively associated with warmth.

The results for harsh parenting are reported in the right-hand columns of Table 2 . The regression indicates that depression was positively associated with harsh parenting. A one-point increase in depression score was associated with a 0.042 -point increase in harsh parenting $(p<.001)$. Under rules for the interpretation of regression coefficient magnitude (Ho囚mann \& Shafer, 2015), the standardized regression coefficient (not reported) indicates that depression was moderately associated with the use of harsh parenting techniques $(B=0.255)$. Unlike with paternal warmth, and contrary to an initial hypothesis, analyses indicate that paternal efficacy was not associated with the use of harsh parenting techniques in this sample. Analyses of control variables indicate that black fathers were more likely than white fathers to use harsh parenting with their children. Paternal age was negatively associated with harsh parenting, and the fathers of girls were less likely to use such techniques. Closed maternal gatekeeping was associated with an increased risk of using harsh parenting techniques.

The results of the interactive models are reported in Table 3. As noted earlier, Hoffmann and Shafer (2015) recommended standardization of both the outcome variable and the depression score, continuous in these models. Doing so improves interpretability and reduces the likelihood of collinearity in the models. In the interactive model, PSE moderated the relationship between paternal depression and warmth. However, contrary to the initial hypothesis, the effect of depression on harsh parenting was not moderated by PSE.

This interaction between depression and PSE on warmth is graphed in Figure 1 for interpretive purposes. In addition, the simple slopes for each group 
Table 2: Main Effects OLS Regression Models for Paternal Warmth and the Use of Harsh Parenting Techniques

\begin{tabular}{|c|c|c|c|c|}
\hline \multirow[b]{2}{*}{ Variable } & \multicolumn{2}{|c|}{ Paternal Warmth } & \multicolumn{2}{|c|}{ Harsh Parenting } \\
\hline & $\boldsymbol{b}$ & (SE) & $\boldsymbol{b}$ & (SE) \\
\hline Depression score & $-0.052^{* *}$ & $(0.018)$ & $0.042^{* * *}$ & $(0.007)$ \\
\hline \multicolumn{5}{|l|}{ Paternal efficacy ${ }^{\mathrm{a}}$} \\
\hline Average & $-1.212^{* * *}$ & $(0.332)$ & -0.182 & $(0.119)$ \\
\hline Low & $-2.454^{* * *}$ & $(0.419)$ & -0.182 & $(0.148)$ \\
\hline \multicolumn{5}{|l|}{ Father's race ${ }^{b}$} \\
\hline Non-Hispanic black & -0.444 & $(0.501)$ & $0.663^{* *}$ & $(0.208)$ \\
\hline Latino/Hispanic & 0.059 & $(0.395)$ & 0.207 & $(0.163)$ \\
\hline Other racial/ethnic identity & -0.500 & $(0.494)$ & 0.023 & $(0.171)$ \\
\hline Father's age & -0.012 & $(0.019)$ & $-0.022^{* *}$ & $(0.007)$ \\
\hline \multicolumn{5}{|l|}{ Father's income ${ }^{c}$} \\
\hline$\$ 20,001-\$ 40,000$ & -0.688 & $(0.593)$ & 0.183 & $(0.201)$ \\
\hline$\$ 40,001-\$ 60,000$ & -0.719 & $(0.580)$ & 0.166 & $(0.197)$ \\
\hline$\$ 60,001-\$ 80,000$ & -0.706 & $(0.629)$ & 0.048 & $(0.207)$ \\
\hline$\$ 80,001-\$ 100,000$ & -1.224 & $(0.665)$ & 0.271 & $(0.249)$ \\
\hline More than $\$ 100,000$ & -0.376 & $(0.649)$ & 0.316 & $(0.236)$ \\
\hline \multicolumn{5}{|l|}{ Father's education $^{\mathrm{d}}$} \\
\hline High school graduate & -1.487 & $(0.760)$ & 0.425 & $(0.240)$ \\
\hline Some college & -0.258 & $(0.702)$ & 0.226 & $(0.207)$ \\
\hline College graduate or more & -0.542 & $(0.728)$ & 0.301 & $(0.216)$ \\
\hline Currently unemployed & 0.300 & $(0.427)$ & -0.079 & $(0.145)$ \\
\hline \multicolumn{5}{|l|}{ Total number of children ${ }^{e}$} \\
\hline 2 & 0.518 & $(0.353)$ & 0.051 & $(0.123)$ \\
\hline 3 & 0.641 & $(0.432)$ & 0.121 & $(0.165)$ \\
\hline 4 or more & 0.383 & $(0.472)$ & -0.043 & $(0.164)$ \\
\hline Child is nonbiological (versus biological) & $-1.277^{* *}$ & $(0.466)$ & -0.121 & $(0.146)$ \\
\hline Child is female (versus male) & $0.976^{* * *}$ & $(0.283)$ & $-0.382^{* * *}$ & $(0.095)$ \\
\hline Child is nonresidential (versus residential) & -0.410 & $(0.768)$ & -0.396 & $(0.204)$ \\
\hline Closed maternal gatekeeping & $-0.147^{* * *}$ & $(0.023)$ & $0.064^{* * *}$ & $(0.008)$ \\
\hline Co-parenting & $0.382^{* * *}$ & $(0.072)$ & -0.031 & $(0.024)$ \\
\hline Constant & $27.806^{* * *}$ & & -0.053 & \\
\hline Observations & 1,156 & & 1,156 & \\
\hline$R^{2}$ & 0.237 & & 0.236 & \\
\hline
\end{tabular}

Notes: OLS = ordinary least squares; $S E=$ standard error.

${ }^{a}$ Reference category is high paternal efficacy.

${ }^{\mathrm{b}}$ Reference category is non-Hispanic white.

'Reference category is $\$ 0-\$ 20,000$.

dReference category is did not complete high school.

e Reference category is one child.

${ }^{*} p<.05 .{ }^{* *} p<.01 .{ }^{* * *} p<.001$.

are displayed in the graph. The results indicate that depression did not have a statistically significant association with paternal warmth for men with high levels of parental self-efficacy. Meanwhile, the association between warmth and depression was negative for both the average $(b=-0.099, p<.05)$ and low $(b=-0.121, p<.01)$ paternal efficacy groups. The results in Table 3 indicate that whereas the difference between fathers in the low and average efficacy groups were not significantly different from one another, the difference between high efficacy and low efficacy was significant. Together, these results suggest that high PSE moderates the negative effect of depression on paternal warmth.

\section{DISCUSSION}

Recently, several studies have focused on PSE with attention to effects and resilience. Those limited studies on PSE have demonstrated a strong association between PSE and paternal involvement (Kwok et al., 2013; Trahan, 2018). They have also 
Table 3: Interactive OLS Regression

Models for Paternal Warmth and the Use of Harsh Parenting Techniques

\begin{tabular}{lll} 
& $\begin{array}{c}\text { Paternal } \\
\text { Warmth }\end{array}$ & $\begin{array}{c}\text { Harsh } \\
\text { Parenting }\end{array}$ \\
\hline Depression score & 0.037 & $0.169^{* *}$ \\
& $(0.061)$ & $(0.057)$ \\
Paternal efficacy & \\
$\quad$ Average & & \\
& $-0.292^{* * *}$ & -0.075 \\
Low & $(0.072)$ & $(0.058)$ \\
& $-0.489^{* * *}$ & 0.021 \\
Interaction effects & $(0.082)$ & $(0.064)$ \\
$\quad$ Depression $\times$ average & -0.136 & -0.417 \\
$\quad$ efficacy & & \\
& $(0.077)$ & $(0.067)$ \\
\multicolumn{1}{c}{ Depression $\times$ low efficacy } & $-0.157^{*}$ & 0.098 \\
& $(0.078)$ & $(0.071)$ \\
Constant & 0.048 & 0.341 \\
Observations & 1,156 & 1,156 \\
$R^{2}$ & 0.229 & 0.201 \\
\hline
\end{tabular}

Note: Models include controls for father's race, age, income, education, employment status; total number of children; if focal child is nonbiological; if focal child is female; if focal child is nonresidential; closed maternal gatekeeping; and co-parenting quality.

Robust standard errors in parentheses.

Reference category is high paternal efficacy.

${ }^{*} p<.05 .{ }^{* *} p<.01 .{ }^{* *} p<.001$

demonstrated that PSE is a crucial resilience factor in potentially adverse social contexts (PagorekEshel \& Dekel, 2015). The present study attempted to bolster this theory by analyzing the effect of PSE on risk factors of depression, harsh parenting, and warmth. Whereas PSE and depression have been previously linked (Wilson \& Durbin, 2010), the addition of harsh parenting and warmth provided the analysis with a rich interpretation of the interactions between these factors.

The results of this study suggest that PSE provides resilience in parenting engagement for fathers suffering from depression. More specifically, a high level of PSE may increase a depressed father's warmth with his children. It also appears that low levels of PSE are associated with low levels of parenting warmth. This finding highlights the importance of building father confidence in the parenting realm for fathers who suffer with moodrelated problems in the early years of their child's life, as engagement in the early infant stage has more potential for bolstering PSE over time (Tremblay \& Pierce, 2011).

These findings support prior research about the association between parenting and depression. In concordance with Wilson and Durbin (2010), this sample demonstrated a positive relationship between depression and paternal warmth. Depression has previously been linked to parenting self-efficacy in mothers (Kunseler, Willemen, Oosterman, \& Schuengel, 2014; Leahy-Warren, McCarthy, \& Corcoran, 2012), and more recently in fathers (Finzi-Dottan, Dayan-Gazith, Borosh, \& Golubchik, 2016; Heerman, Taylor, Wallston, \& Barkin, 2017). In an Israeli sample, previous study results demonstrated that PSE is related to a father's warmth and caregiving (Finzi-Dottan et al., 2016). The results of this study mirror these findings in a U.S. population, with further distinctions. Specifically, PSE both correlates with warmth and acts as a moderator to the relationship between depression and warmth. Thus, when PSE is high, effectively depressed fathers are warmer toward their children, increasing potential for positive exchange. As statistics indicate increased risk for paternal depression during the early years of parenting a child, with potential for ongoing depressive symptoms after infancy, PSE may be a critical factor for parenting engagement.

Whereas depression and harsh parenting were associated in this analysis, PSE had little effect on the relationship between these two variables. It may be that harsh parenting practices are less likely to be influenced by a father's competence in the parenting realm, and more likely influenced by mood-related symptoms from depression. As PSE is not related to the relationship between depression and fathering, we suspect that depressed fathers may be less likely to externalize their insecurities within the parenting realm and may be more likely to detach and withdraw from parenting engagement.

\section{Limitations and Future Directions}

This study contributes to the research of PSE by evaluating the intersection with various risk factors. There are limitations to this study. First, the sample is not a nationally representative U.S. sample. Although the sample size is adequately powered, there are limitations to generalizability with quota sampling. Quota sampling may not be generalizable (Yang \& Banamah, 2014) and, thus, must be interpreted as exploratory in nature. Quota sampling with a computer survey may also present potential problems with confirming the identity of the respondent (Im \& Chee, 2011). Of note, with this quota sample, racial demographic breakdown does come close to matching U.S. Census Bureau statistics of racial household composition but does not 


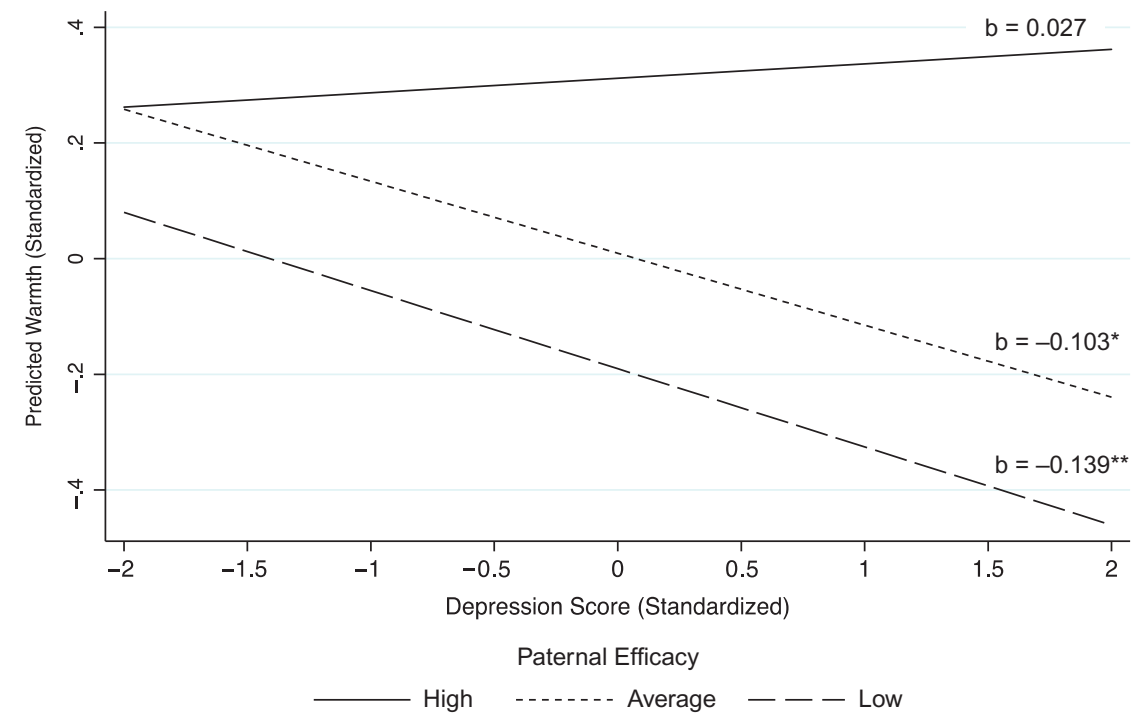

adequately represent households of single mothers and nonresident fathers (U.S. Census Bureau, 2016b). The survey is cross-sectional and does not make any approximation of causation. Although PSE may moderate the relationship between paternal engagement and warmth, cross-sectional research is limited in support for causal inference. Furthermore, experimental design focused on interventions for PSE with depressed fathers may produce a clearer understanding of the order of these relationships and the effect of PSE on outcomes for depressed fathers, such as warmth and harsh parenting.

A second limitation to the study is the use of a single item to measure PSE. It could be argued that this single-item measurement for PSE does not robustly measure the construct of a sense of agency within the parenting realm. In addition, it may be conferred that fathers who answer the item are distinctly focused on a situation or event, which does not translate to a global representation of overall PSE. The item pertaining to self-efficacy was worded in the negative (that is, how often a father feels that he cannot handle being a parent), which may have been misinterpreted. This limitation to our measurement construct should encourage caution when interpreting these results.

The third limitation of this study is the potential of bias related to online survey completion. Previously stated, online survey research primarily appeals to a higher-SES pool of respondents. Families with less than $\$ 25,000$ per year are only likely to access the Internet half the time at home, whereas families with incomes above $\$ 100,000$ are likely to access the Internet close to $100 \%$ of the time (Dolan, 2016). Access to a computer to answer surveys may also be dependent on time, minority status, age, education, and urban location (Calvert, Rideout, Woolard, Barr, \& Strouse, 2005; Cleary, Piece, \& Trauth, 2005; Dolan, 2016). Online survey research may also be subject to self-selection bias, with respondents choosing study participation due to level of interest in study content (Bethlehem, 2010). As online survey research has limitations, we again suggest caution in interpretation of results.

\section{Implications}

This study contributes to a knowledge base about factors determining level of paternal engagement in family systems. As family demography indicates a growing diversity of family composition, factors that can consistently and reliably contribute to parenting behavior are valuable and worthy of research attention. Over the past 20 years, parenting self-efficacy is a relatively well-researched field (Jones \& Prinz, 2005). However, as parenting selfefficacy studies have not had equal representation of 
mothers and fathers (Jones \& Prinz, 2005; Trahan, 2018), there is a gap in knowledge of the impact of this dimension in father engagement. This study's result that PSE is related to paternal warmth with children ages two to eight years builds on a research foundation of the importance of PSE in the very early stages of a child's life (Tremblay \& Pierce, 2011) and implies that this factor is important into the toddler- and school-age years.

In addition, the result that depression is moderated by the presence of PSE indicates that PSE is a resilience factor for mental health. For fathers who exhibit a strong sense of PSE, depression symptoms are lessened. However, as this study did not evaluate causality, we cannot interpret the results to mean that PSE is the cause of such a decrease. Depression may affect the process of building confidence in the parenting realm. Further research comparing interventions on both depression and PSE may be necessary to determine the best clinical method for maximizing outcomes. SWR

\section{REFERENCES}

Addis, M. E. (2008). Gender and depression in men. Clinical Psychology, Science and Practice, 15(3), 153-168.

Allen, S. M., \& Hawkins, A. J. (1999). Maternal gatekeeping: Mothers' beliefs and behaviors that inhibit greater father involvement in family work. Journal of Marriage and Family, 61, 199-212.

Baker, C. (2014). African-American fathers' depression and stress as predictors of father involvement during early childhood. Journal of Black Psychology, 40, 311-333.

Baker, R., Blumberg, S. J., Brick, J. M., Couper, M. P., Courtright, M., Dennis, J. M., et al. (2010). AAPOR report on online panels. Public Opinion Quarterly, 74, 711-781.

Bandura, A. (1977). Self-efficacy: Toward a unifying theory of behavioral change. Psychological Review, 84(2), 191-215.

Bethlehem, J. (2010). Selection bias in Web surveys. International Statistics Review, 78(2), 161-188.

Bianchi, S. M., Robinson, J. P., \& Milke, M. A. (2006). Changing rhythms of American family life. New York: Russell Sage Foundation.

Blackwell, D. L., Lucas, J. W., \& Clarke, T. C. (2014). Summary health statistics for US adults: National Health Interview Survey, 2012. Vital and health statistics. Series 10, Data from the National Health Survey, 2014(260), 1-161.

Bornstein, M. H., \& Bradley, R. H. (Eds.). (2014). Socioeconomic status, parenting, and child development. New York: Routledge.

Boyraz, G., \& Sayger, T. V. (2011). Psychological wellbeing among fathers of children with and without disabilities: The role of family cohesion, adaptability, and paternal self-efficacy. American Journal of Men's Health, 5, 286-296.

Breusch, T. S., \& Pagan, A. R. (1980). The Lagrange multiplier test and its applications to model specifications in econometrics. Review of Economic Studies, 47(1), 239-254.
Bronte-Tikew, J., Moore, K. A., Matthews, G., \& Carrano, J. (2007). Symptoms of major depression in a sample of fathers of infants: Sociodemographic correlates and links to father involvement. Journal of Family Issues, 28(1), 61-99.

Cabrera, N., Fitzgerald, H. E., Bradley, R. H., \& Roggman, L. (2014). The ecology of father-child relationships: An expanded model. Journal of Family Theory \& Review, 6, 336-354

Calvert, S., Rideout, V., Woolard, J., Barr, R., \& Strouse, G. (2005). Age, ethnicity, and socioeconomic patterns in early computer use: A national survey. American Behavioral Scientist, 48, 590-607.

Cameron, E. E., Sedov, I. D., \& Tomfohr-Madsen, L. M. (2016). Prevalence of paternal depression in pregnancy and the postpartum: An updated meta-analysis. Journal of Affective Disorders, 206, 189-203.

Cleary, P., Piece, G., \& Trauth, E. (2005). Closing the digital divide: Understanding racial, ethnic, social class, gender, and geographic disparities in Internet use among school age children in the United States. Universal Access in the Information Society, 4, 354-373.

Comstock, G. W., \& Helsing, K. J. (1976). Symptoms of depression in two communities. Psychological Medicine, 6, 551-563.

Dolan, J. (2016). Splicing the divide. A review of research on the evolving digital divide among K-12 students. Journal of Research on Technology in Education, 48(1), 16-37.

Elliott, M. (2001). Gender differences in causes of depression. Women \& Health, 33(3-4), 183-198.

Epkins, C. C., \& Harper, S. L. (2016). Mothers' and fathers' parental warmth, hostility/rejection/neglect, and behavioral control: Specific and unique relations with parents' depression versus anxiety symptoms. Parenting: Science \& Practice, 16(2), 125-145.

Fagan, J., \& Barnett, M. (2003). The relationship between maternal gatekeeping, paternal competence, mothers' attitudes about the father role, and father involvement. Journal of Family Issues, 24, 1020-1043.

Finzi-Dottan, R., Dayan-Gazith, E., Borosh, T., \& Golubchik, P. (2016). Involvement and warmth of fathers with mental illness: The role of caregiving system, parental self-efficacy, social support and child characteristics. Community Mental Health Journal, 52, 972-982.

Flouri, E. (2005). Fathering and child outcomes. Hoboken, NJ: Wiley.

Garfield, C. F., Duncan, G., Rutsohn, J., McDade, T. W., Adam, E. K., Levine Coley, R., \& Chase-Lansdale, P. L. (2014). A longitudinal study of paternal mental health during transition to fatherhood as young adults. Pediatrics, 133, 836-843.

Giallo, R., D’Esposito, F., Cooklin, A., Christensen, D., \& Nicholson, J. M. (2014). Factors associated with trajectories of psychological distress for Australian fathers across the early parenting period. Social Psychiatry and Psychiatric Epidemiology, 49, 1961-1971.

Gladstone, T.R.G., Beardslee, W. R., \& Diehl, A. (2015). The impact of parental depression on children. In A. E. Reupert, D. Maybery, J. Nicholson, M. Gopfert, \& M. V. Seeman (Eds.), Parental psychiatric disorder: Distressed parents and their families (3rd ed., pp. 117-126). Cambridge, England: Cambridge University Press.

Glidewell, J. C., \& Livert, D. E. (1992). Confidence in the practice of clinical psychology. Professional Psychology: Research and Practice, 32, 362-368.

Goodman, S. H., Rouse, M. H., Connell, A. M., Broth, M. R., Hall, C. M., \& Heyward, D. (2011). Maternal depression and child psychopathology: A metaanalytic review. Clinical Child and Family Psychology Review, 14(1), 1-27. 
Greenberg, P. E., Fournier, A. A., Sisitksy, T., Pike, C. T., \& Kessler, R. C. (2015). The economic burden of adults with major depressive disorder in the United States (2005 and 2010). Journal of Clinical Psychiatry, 76, 155-162.

Heerman, W., Taylor, J., Wallston, K., \& Barkin, S. (2017). Parenting self-efficacy, parent depression and healthy childhood behaviors in a low-income minority population: A cross-sectional analysis. Maternal and Child Health Journal, 21, 1156-1165.

Hoffmann, J. P., \& Shafer, K. (2015). Linear regression analysis: Assumptions and applications. Washington, DC: NASW Press.

Huber, P. J. (1967). The behavior of maximum likelihood estimates under non-standard conditions. Proceedings of the Fifth Berkeley Symposium on Mathematical Statistics and Probability (Vol. 1, pp. 221-233). Berkeley: University of California Press.

Im, E., \& Chee, W. (2011). Quota sampling in Internet research: Practical issues. Computers, Informatics, Nursing, 29, 381-385.

Jones, T. L., \& Prinz, R. J. (2005). Potential roles of parental self-efficacy in parent and child adjustment: A review. Clinical Psychology Review, 25, 341-363.

Kessler, R. C., Berglund, P., Demler, O., Jin, R., Koretz, D., Merikangas, K. R., et al. (2003). The epidemiology of major depressive disorder: Results from the National Comorbidity Survey Replication (NCS-R). JAMA, 289, 3095-3105.

Kim, G., DeCoster, J., Huang, C. H., \& Chiriboga, D. A (2011). Race/ethnicity and the factor structure of the Center for Epidemiologic Studies Depression Scale: A meta-analysis. Cultural Diversity and Ethnic Minority Psychology, 17, 381-396.

Kotch, J. B., Smith, J., Margolis, B., Black, M., English, D., Thompson, R., et al. (2014). Does social capital protect against the adverse behavioral outcomes of child neglect? Child Abuse Review, 23(4), 246-261.

Kunseler, F., Willemen, A. M., Oosterman, M., \& Schuengel, C. (2014). Changes in parenting self-efficacy and mood symptoms in the transition to parenthood: A bidirectional association. Parenting: Science and Practice, 14(3-4), 215-234.

Kwok, S., Ling, C., Leung, C., \& Li, J. (2013). Fathering self-efficacy, marital satisfaction and father involvement in Hong Kong. Journal of Family Studies, 22, $1051-1060$

Lampard, A. M., Franckle, R. L., \& Davison, K. K. (2014). Maternal depression and childhood obesity: A systematic review. Preventive Medicine, 59, 60-67.

Leahy-Warren, P., McCarthy, G., \& Corcoran, P. (2012). First-time mothers: Social support, maternal parental self-efficacy, and postnatal depression. Journal of Clinical Nursing, 21, 388-397.

Lee, S., Altschul, I., \& Gershoff, E. T. (2015). Wait until your father gets home? Mother's and fathers' spanking and development of child aggression. Children and Youth Services Review, 52, 158-166.

Leerkes, E. M., \& Burney, R. V. (2007). The development of parenting efficacy among new mothers and fathers. Infancy, 12(1), 45-67.

Leung, D. W., \& Slep, A. M. (2005). Predicting inept discipline: The role of parental depressive symptoms, anger, and attributions. Journal of Consulting and Clinical Psychology, 74, 524-534.

Little, R.J.A. (1988). A test of missing completely at random for multivariate data with missing values. Journal of the American Statistical Association, 83, 1198-1202.

McLaughlin, K. (2011). The public health impact of major depression: A call for interdisciplinary prevention efforts. Prevention Science, 12, 361-371.
Morris, T. L., \& Oosterhoff, B. (2016). Observed mother and father rejection and control: Association with child social anxiety, general anxiety, and depression. Journal of Child and Family Studies, 25, 2904-2914.

Murdock, K. W. (2013). An examination of parenting selfefficacy among mothers and fathers. Psychology of Men and Masculinity, 14, 314-323.

Nath, S., Russell, G., Ford, T., Kuyken, G., \& Psychogio, L. (2015). Postnatal paternal depressive symptoms associated with fathers' subsequent parenting: Findings from the Millennium Cohort Study. British Journal of Psychiatry, 207, 558-559.

National Research Council \& Institute of Medicine. (2009). Depression in parents, parenting, and children: Opportunities to improve identification, treatment, and prevention. Washington, DC: National Academies Press.

Pagorek-Eshel, S., \& Dekel, R. (2015). Parental selfefficacy and paternal involvement in the context of political violence. Clinical Social Work Journal, 43, 388-397. doi:10.1007/s10615-015-0516-7

Palkovitz, R., Fagan, J., \& Hull, J. (2013). Co-parenting and children's well-being. In N. J. Cabrera \& C. S. Tamis-LeMonda (Eds.), Handbook of father involvement: Multi-disciplinary perspectives (2nd ed., pp. 202-219). New York: Routledge/Taylor and Francis Group.

Paulson, J. F., \& Bazemore, S. D. (2010). Prenatal and postpartum depression in fathers and its association with maternal depression: A meta-analysis. JAMA, 303, 1961-1969.

Petts, R. J., Shafer, K., \& Essig, L. W. (2018). Does adherence to masculine norms shape fathering behavior? Journal of Marriage and Family, 80, 704-720.

Pew Research Center. (2016). Internet/broadband fact sheet. Retrieved from http://www.pewinternet.org

Pilowsky, D. J., Wickramaratne, P., Poh, E., Hernandez, M., Batten, L. A., Flament, M. F., et al. (2014). Psychopathology and functioning among children of treated depressed fathers and mothers. Journal of Affective Disorders, 164(1), 107-111.

Sevigny, P. R., \& Loutzenhiser, L. (2010). Predictors of parenting self-efficacy in mothers and fathers of toddlers. Child: Care, Health and Development, 36(2), 179-180.

Shafer, K., Fielding, B., \& Holmes, E. K. (2019). Depression, masculine norm adherence, and fathering behavior. Journal of Family Issues, 40(1), 48-84.

Shafer, K., Fielding, B., \& Wendt, D. (2017). Similarities and differences in the influence of paternal and maternal depression on adolescent well-being. Social Work Research, 41, 85-96.

Shafer, K., \& Wendt, D. (2015). Men's mental health: A call to social workers. Social Work, 60, 105-112.

Singley, D. B., \& Edwards, L. M. (2015). Men's perinatal mental health in the transition to fatherhood. Professional Psychology: Research and Practice, 46, 309-316.

Smith, S. M., Roster, C. A., Linda, L. G., \& Gerald, S. A. (2016). A multi-group analysis of online survey respondent data quality: Comparing a regular USA consumer panel to MTurk samples. Journal of Business Research, 69, 3139-3148.

Surkan, P., Kennedy, C., Hurley, K., \& Black, M. (2011). Maternal depression and early childhood growth in developing countries: Systematic review and metaanalysis. Bulletin of the World Health Organization, 89, 607-615D.

Terhanian, G., Bremer, J., Olmsted, J., \& Guo, J. (2016). A process for developing an optimal model for reducing bias in nonprobability samples. Journal of Advertising Research, 56, 14-24.

Tourangeau, R., Conrad, F. G., \& Couper, M. P. (2013). The science of web surveys. New York: Oxford University Press. 
Trahan, M. H. (2018). Paternal self-efficacy and father involvement: A bi-directional association. Psychology of Men E Masculinity, 19, 624-634. doi:10.1037/ men0000130

Tremblay, S., \& Pierce, T. (2011). Perceptions of fatherhood: Longitudinal reciprocal associations within the couple. Canadian Journal of Behavioral Science, 43(2), 99-110.

U.S. Census Bureau. (2016a). 2011-2014 American Community Survey [Summary File]. Retrieved from http:// ftp2.census.gov

U.S. Census Bureau. (2016b). The majority of children live with two parents, Census Bureau reports. Retrieved from https://www.census.gov/newsroom/press-releases/ 2016/cb16-192.html

Weinberg, J. D., Freese, J., \& McElhattan, D. (2014). Comparing data characteristics and results of an online factorial survey between a population-based and a crowdsource-recruited sample. Sociological Science, 1, 292-310.

White, H. (1980). A heteroskedasticity-consistent covariance matrix estimator and a direct test for heteroskedasticity. Econometrica, 48, 817-838.

Wilson, S., \& Durbin, E. C. (2010). Effects of paternal depression on fathers' parenting behaviors: A metaanalytic review. Clinical Psychology Review, 30(2), $167-180$.

Wittkowski, A., Garrett, C., Calam, R., \& Weisberg, D. (2017). Self-report measures of parenting self-efficacy: A systematic review of current literature. Journal of Child and Family Studies, 26, 2960-2978.

Yang, K., \& Banamah, A. (2014). Quota sampling as an alternative to probability sampling? An experimental study. Sociological Research Online, 19(1), 24-32.

Mark Herrick Trahan, PhD, LCSW, is assistant professor, School of Social Work, Texas State University, 601 University Drive, San Marcos, TX 78640; e-mail: marktrahan@txstate.edu. Kevin Shafer, PhD, is associate professor, Brigham Young University, Provo, UT.

Original manuscript received October 2, 2017

Final revision received July 1, 2018

Editorial decision July 16, 2018

Accepted July 19, 2018

Advance Access Publication March 27, 2019

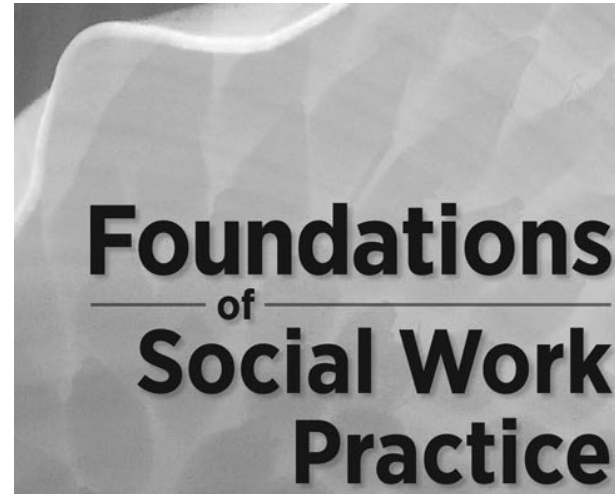

A Graduate Text, 5th Edition

Edited by Mark A. Mattaini and Casey Holtschneider with Christine T. Lowery

7

Whe fifth edition of Foundations of

Social Work Practice: A Graduate Text outlines and integrates ecological and structural theories of social work practice to ground social work students in a more balanced and comprehensive understanding of how social work supports social justice.

Throughout, Foundations of Social Work Practice incorporates evidenceinformed practice models with principles of structural practice, placing constant emphasis on the need to challenge structural injustice while supporting the casualties of that injustice, working to realize a progressive vision of a just and caring society.

ISBN: 978-0-87101-502-0 2016 Item \#5020 312 pages $\$ 49.99$

1-800-227-3590 www.naswpress.org

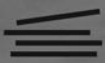

NASW PRESS 


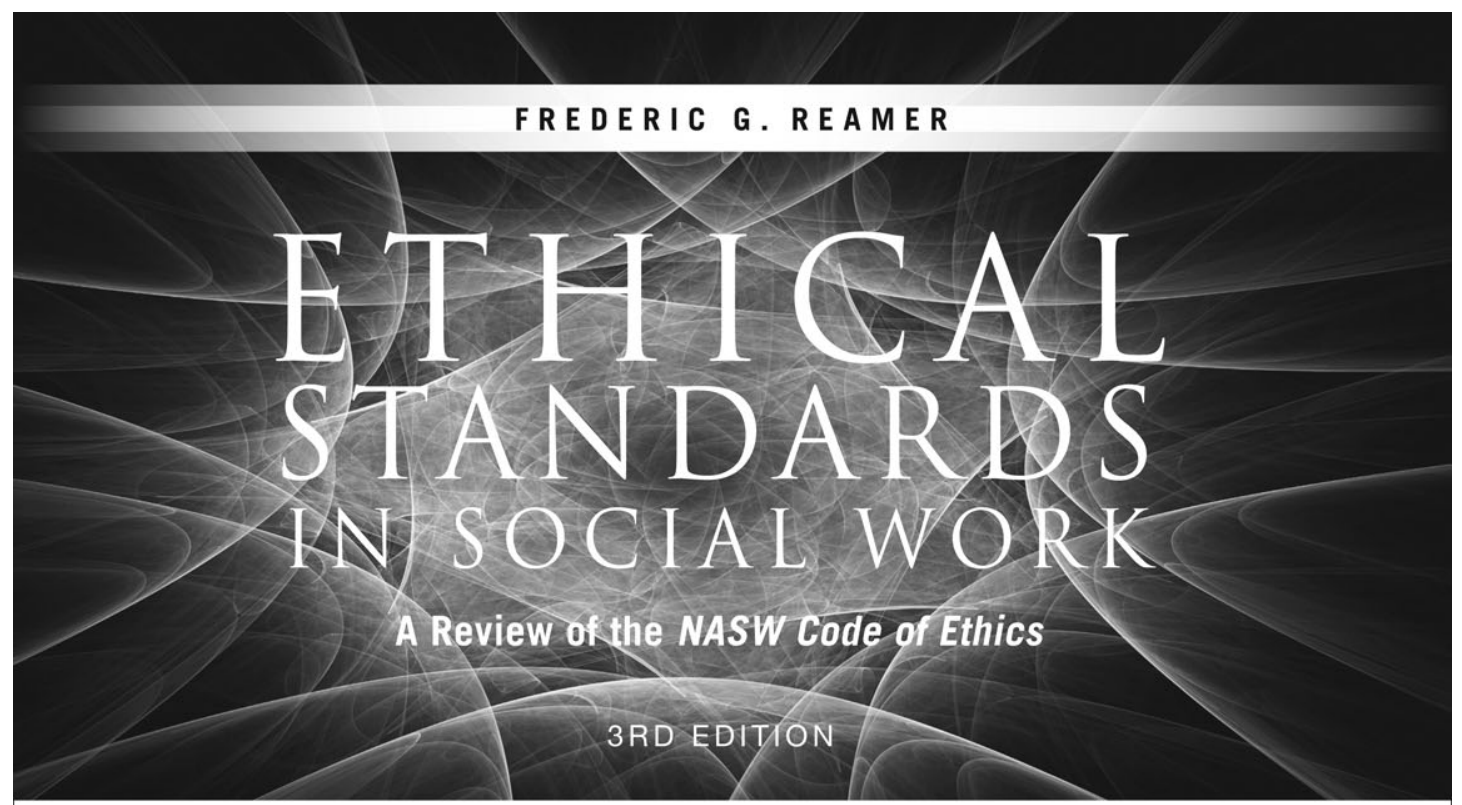

- Essential ethics content that is a required element in social work education programs

- Extensive application of the NASW Code of Ethics to case examples

- Evolution of ethical issues in the social work profession

- Relevant curriculum content in the areas of clinical practice; social policy; social work administration; community practice; research and evaluation; and cultural, ethnic, and social diversity

- Cutting-edge content on ethical challenges associated with social workers' use of digital and other technology 


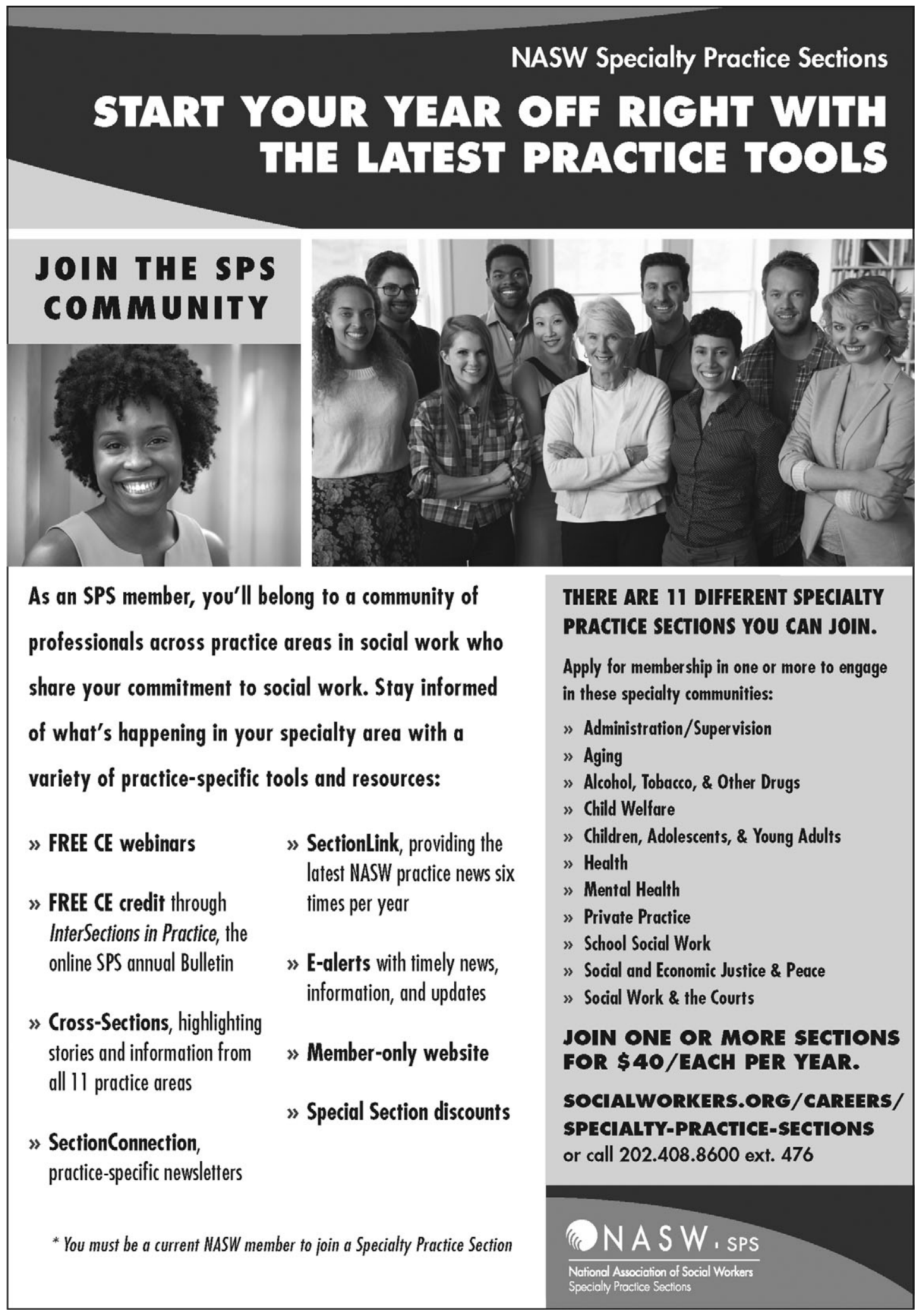

